\title{
MODEL PEMBELAJARAN KEWIRAUSAHAAN DENGAN MEDIA KOPERASI SEKOLAH DI SMK KELOMPOK BISNIS DAN MANAJEMEN
}

\author{
Iin Nurbudiyani \\ FKIP Universitas Muhammadiyah Palangkaraya \\ iin_nurbudiyani@yahoo.co.id
}

Abstrak

\begin{abstract}
Penelitian bertujuan menghasilkan: (1) model pembelajaran Model Kwu-Kop yang dapat menumbuhkan keterampilan kewirausahaan siswa SMK; (2) perangkat pembelajaran Model KwuKop yang dapat dipergunakan di SMK; (3) model pembelajaran kewirausahaan yang memenuhi kriteria valid dan efektif; dan (4) model pembelajaran yang dapat dilaksanakan dan berfungsi dengan baik untuk menumbuhkan keterampilan kewirausahaan siswa SMK. Metode yang digunakan adalah penelitian dan pengembangan $(R \& D)$. Tahap pengembangan terdiri empat tahap yaitu: (1) investigasi ; (2) perancangan; (3 realisasi; dan (4) evaluasi. Produk yang dihasilkan divalidasi oleh ahli materi dan ahli pendidikan. Penilaian dilakukan sebanyak dua kali, yaitu: (1) pra-ujicoba terbatas, dan (2) setelah ujicoba terbatas. Tingkat kesepakatan antar penilai dianalisis dengan statistik Coeffisient Cohen's Kappa dan Percentage of Agreement. Hasil penelitian adalah: (1) pengembangkan Model Kwu-Kop terbagi dalam dua kegiatan, yaitu: (a) pra-pengembangan, meliputi tahap investigasi, tahap perancangan, tahap realisasi; dan (b) pengembangan, meliputi tahap evaluasi; (2) perangkat model yang dihasilkan adalah buku panduan Model Kwu-Kop lengkap dengan perangkat pembelajaran (RPP, modul, job sheet dan alat evaluasi); (3) model yang dihasilkan memenuhi kriteria valid dan efektif; dan (4) Model Kwu-Kop dapat dilaksanakan dan berfungsi dengan baik untuk menumbuhkan keterampilan kewirausahaan siswa SMK.
\end{abstract}

Kata kunci: model pembelajaran, kewirausahaan, SMK kelompok bisnis dan manajemen, koperasi sekolah.

\section{A SCHOOL COOPERATIVE-BASED ENTREPRENEURSHIP LEARNING MODEL IN THE VOCATIONAL HIGH SCHOOL OF BUSINESS AND MANAGEMENT GROUP}

\begin{abstract}
The objectives of this study are to develop: (1) the school cooperative-based entrepreneurship learning model (SC-ELM) that can build entrepreneurial skills among students in vocational high school (SMK); (2) a set of SC-ELM that can be used in SMK; (3) SC-ELM that can meet validity and effectiveness criteria; and (4) SC-ELM that can be applied and serve well to build the entrepreneurial attitudes and skills of SMK students. This study used the ' $R \& D^{\prime}$ ' method. The development consisted of four steps, i.e.: (1) investigation; (2) designing; (3) realization; and (4) evaluation. The resultant products were validated by the experts in both learning material and education. Assessment was done twice: (1) limited pre-test and (2) post-test. To measure the level of inter-rater consensus by the experts, an analysis was done by using the statistic tests for the Coefficient Cohen's Kappa and the Percentage of Agreement. The results of the study are as follows. (1) The development of SC-ELM is divided into two types of activity, i.e. (a) predevelopment step, including investigation, designing, and realization; and (b) development, including evaluation. (2) The developed model consists of the manual of SC-ELM and a set of lesson plans (RPP, module, job sheet, and evaluation instrument). (3) The resultant model meets the validity and effectiveness criteria. (4) SC-ELM can be applied and serve well to build the entrepreneurial attitudes and skills of SMK students.
\end{abstract}

Keywords: learning model, entrepreneurship, vocational high school, business and management group, school cooperative 


\section{PENDAHULUAN}

\section{Latar Belakang Masalah}

Pendidikan Nasional bertujuan untuk mencerdaskan bangsa dan mengembangkan manusia Indonesia seutuhnya berdasarkan Pancasila dan UUD 1945. Pendidikan nasional diharapkan menghasilkan manusia terdidik yang beriman, bertaqwa, berbudi pekerti luhur, berpengetahuan, berketerampilan, berkepribadian dan bertanggung jawab. Sesuai PP No 19 tahun 2005 tentang Standar Nasional Pendidikan, dinyatakan bahwa pelaksanaan pendidikan di setiap institusi pendidikan harus sesuai dengan Standar Nasional Pendidikan, yaitu standar minimal tentang sistem pendidikan diseluruh wilayah Indonesia dan berfungsi sebagai dasar dalam perencanaan, pelaksanaan dan pengawasan pelaksanaan pendidikan dalam rangka mewujudkan pendidikan yang bermutu. Hal tersebut diperlukan terutama untuk mengantisipasi pasar bebas, terutama di lingkungan negara-negara ASEAN, seperti: AFTA, AFLA dan APEC.

Jumlah pengangguran pada Agustus 2008 berdasarkan tingkat pendidikan paling banyak dari lulusan Sekolah Menengah Kejuruan (SMK). Data Badan Pusat Statistik atau BPS menyebutkan lulusan SMK yang menganggur berada pada angka tetinggi yaitu $17,26 \%$, disusul tamatan SMA 14,31\%, lulusan Universitas $12,59 \%$, serta Diploma I/II/III adalah 11,21\%. Sedangkan tamatan SMP ke bawah justru paling sedikit menganggur yaitu 4,57\% untuk SD, dan 9,39\% untuk SMP (BPS Maret 2009). Hal ini menunjukkan bahwa ternyata sebagian lulusan SMK belum memanfaatkan kemampuan entrepreneur-nya dan cenderung menunggu untuk dapat bekerja di perusahaan.

Sekolah Menengah Kejuruan (SMK) sebagai salah satu lembaga pendidikan mempunyai tujuan menyiapkan lulusan peserta didik agar dapat bekerja secara mandiri sesuai dengan bidang dan program keahlian yang dimiliki. Untuk itu Sekolah Menengah Kejuruan (SMK), harus mampu melahirkan lulusan yang bermutu, memiliki pengetahuan, menguasai teknologi, berketerampilan teknis dan memiliki kecakapan hidup yang memadai. SMK sebagai pendidikan vokasional dituntut untuk menghasilkan tenaga-tenaga profesional yang memiliki kemampuan kewirausahaan, yang menjadi salah satu pilar utama aktivitas perekonomian nasional (Renstra Depdiknas, 2010-2014: 60). Sumber dari PBB (Perserikatan Bangsa Bangsa), yang dikutip oleh Buchari Alma (2005: 4-5), menyatakan bahwa suatu bangsa atau negara akan mampu membangun ekonomi apabila memiliki wirausahawan sebanyak 2\% dari jumlah penduduk. Di Indonesia jumlah wirausahawan sangat sedikit, bahkan dibandingkan dengan negara tetangga seperti Malaysia dan Singapura. Menurut survey Bank Dunia tahun 2008, wirausahawan Malaysia mencapai $4 \%$, Thailand $4,1 \%$, dan Singapura $7,2 \%$, di Indonesia hanya berjumlah 1,56\% (Boediono, 2012).

Pengembangan kewirausahaan sekolah berbasis kreativitas dan inovasi dapat memberikan bekal bagi semua warga sekolah dalam pengelolaan pendidikan, khususnya dalam mempersiapkan "sekolah mandiri" yang menjadi roh dari otonomi sekolah. Oleh sebab itu, desain pembelajaran kewirausahaan di SMK perlu ditinjau ulang, mulai dari kurikulum, strategi pembelajaran, metode pembelajaran, media pembelajaran dan guru yang mengajar mata pelajaran kewirausahaan. Pemanfaatan Koperasi sekolah dapat dijadikan sebagai salah satu media pembelajaran praktik langsung para siswa dalam menerapkan keterampilan dan keahliannya dalam pembelajaran kewirausahaan. Pengelolaan Koperasi sekolah selain sebagai media pembelajaran, juga dapat memberikan sumbangsih dalam menambah penghasilan sekolah dan membantu membangun perekonomian masyarakat.

\section{Kajian Teori}

\section{Kewirausahaan}

Istilah wirausaha merupakan terjemahan dari kata entrepreneur. Dalam bahasa Indonesia, pada awalnya dikenal dengan istilah wiraswasta yang berarti berdiri di atas kekuatan sendiri. Suharsono Sagir dalam Buchari Alma (2005: 18), menuliskan bahwa wiraswasta adalah seorang yang modal utamanya adalah ketekunan yang dilandasi sikap optimis, kreatif dan melakukan usaha sebagai pendiri pertama disertai dengan keberanian menanggung resiko berdasarkan suatu perhitungan dan perencanaan yang tepat. Sedangkan Fadel Muhammad dalam Buchari Alma (2005: 18), lebih menekankan 
bahwa wiraswasta adalah orang yang memfokuskan diri pada peluang, bukan pada resiko. Dengan demikian, wiraswasta bukanlah pengambilan resiko, melainkan penentu resiko.

Irmawita (2003: 45), menyatakan bahwa kemampuan mengembangkan kewirausahaan sangat ditentukan oleh kecakapan dari si pengelola usaha tersebut. Artinya tingkat pendidikan dan pengalaman berpengaruh terhadap pengembangan sebuah usaha disamping modal dan motivasi kerja. Hal ini diperkuat pendapat dari Surya Dharma (2009: 102), bahwa pengembangan kewirausahaan sekolah merupakan trend baru yang mendukung pengembangan suatu pendidikan di berbagai tingkatan pendidikan. Menurut Timmons (Lambing dan Kuehl, 2000: 14), menyatakan pengertian kewirausahaan sebagai berikut:

Entrepreneurship is a human, creative act that builds something of value from practically nothing. It is the pursuit of opportunity regardless of the resources, or lack of resources, at hand. It requires $a$ vision and the passion and commitment to lead others in the pursuit of that vision. It also requires a willingness to take calculated risks.

Artinya, kewirausahaan merupakan sifat manusiawi untuk bertindak kreatif meningkatkan nilai sesuatu dengan memanfaatkan kesempatan dan sumber daya yang dilandasi visi, semangat dan komitmen dalam memimpin serta memperhitungkan resiko. Karena kewirausahaan merupakan sifat manusiawi, maka kewirausahaan berhubungan erat dengan perilaku. Pendapat yang sama dari Hisrich dan Peters (1989: 9), mengenai pengertian entrepreneurship sebagai berikut:

Entrepreneurship is the process of creating something new with value by devoting the necessary time and effort, assuming the accompanying financial, psychic, and social risks, and receiving the resulting rewards of monetary and personal satisfaction and independence.

Pendapat tersebut mempunyai makna bahwa kewirausahaan adalah merupakan suatu proses mengkreasi sesuatu yang baru yang mempunyai nilai, dengan mencurahkan waktu dan upaya, serta berani menanggung resiko untuk mencapai keberhasilan. Jadi pendapat Hisrich dan Peter sejalan dengan pendapat Lambing dan Kuehl, yaitu samasama berpendapat bahwa kewirausahaan adalah proses suatu kegiatan untuk meningkatkan nilai tambah sumber-sumber daya yang ada.

Menurut Zimmerer (2008: 36), Kewirausahaan adalah hasil dari suatu disiplin serta proses sistematis penerapan kreativitas dan inovasi dalam memenuhi kebutuhan dan peluang di pasar. Pendapat yang senada dari Suryana (2003: 2), bahwa kewirausahaan (entrepreneurship) adalah merupakan suatu kemampuan kreatif dan inovasi dalam menciptakan sesuatu yang baru dan bernilai tambah untuk di pasarkan melalui proses pengelolaan sumber daya dengan cara-cara baru dan berbeda, seperti: (1) pengembangan teknologi; (2) penemuan pengetahuan ilmiah; (3) perbaikan produk barang dan jasa yang ada; (4) menemukan cara-cara baru untuk mendapatkan produk yang lebih banyak dengan sumber daya yang lebih efisien. Dari kedua pendapat di atas diketahui bahwa titik kesamaan persepsi kewirausahaan adalah kreativitas dan inovasi.

Sedangkan Kuratko and Hoodgets (2004: 30), mendefinisikan entrepreneurship secara rinci sebagai:

Entrepreneurship is a dynamic process of vision, change, and creation. It requires an application of energy and passion towards the creation and implementation of new ideas and creative solutions. Essential ingredients include the willingness to take calculated risks-in terms of time, equity, or career; the ability to formulate an effective venture team; the creative skill to marshall needed resources; the fundamental skill of building a solid business plan; and, finally, the vision to recognize opportunity where others see chaos, contradiction and confusion.

Pendapat tersebut mempunyai makna bahwa, seorang wirausahawan dalam melakukan aktivitas manajemen strategik dimana dalam keputusan mempertimbangkan kekuatan dan kelemahan wirausaha (internal) dan juga peluang dan hambatan yang ada dalam lingkungan usaha (eksternal), bermanfaat untuk individu dan masyarakat. Depdiknas 
(1998: 156), mengartikan bahwa entrepreneurship (kewirausahaan) adalah sikap dan perilaku dalam memimpin dan mengelola suatu organisasi (termasuk sekolah) dengan selalu mencari dan menerapkan cara kerja dan teknologi baru sehingga dicapai efektivitas dan efisiensi yang tinggi.

Dari beberapa definisi dan uraian di atas maka dapat di simpulkan bahwa kewirausahaan adalah ilmu yang mempelajari tentang nilai, kemampuan, sikap dan perilaku seseorang dalam memenuhi tantangan dalam kehidupannya (individu/organisasi) secara efektif dan efisien sehingga ia mampu mandiri dan dapat mengembangkannya ke arah yang lebih baik, sehingga efektif dan efisien. Seorang wirausahawan adalah seseorang yang selalu berkembang dan mengembangkan setiap potensi dan kemampuan yang dimilikinya.

Seseorang wirausaha haruslah orang yang mampu melihat ke depan, berfikir dengan penuh perhitungan, mencari pilihan dari berbagai alternatif masalah dan dapat mengambil keputusan dengan tepat dan cepat. Menurut B. N. Marbun (Buchori Alma, 2005: 39 ), seorang wirausaha haruslah memiliki ciriciri: (1) percaya diri; (2) berorientasi tugas dan hasil; (3) mengambil resiko; (4) kepemimpinan; (5) keorisinilan; (6) berorientasi kemasa depan.

\section{Koperasi}

Menurut Arifin Chaniago (1982: 1), Koperasi adalah suatu perkumpulan yang beranggotakan orang-orang atau badan-badan, yang memberikan kebebasan masuk dan keluar sebagai anggota, dengan bekerja sama secara kekeluargaan menjalankan usaha, untuk mempertinggi kesejahteraan jasmaniah para anggotanya. Pengertian Koperasi yang senada dikemukakan oleh Margono Djojohadikoesoemo (Hendrojogi, 1999: 21), yang menyatakan bahwa Koperasi ialah perkumpulan manusia yang dengan sukanya sendiri hendak bekerja sama untuk memajukan ekonominya.

Undang-undang No. 25 tahun 1992 tentang Perkoperasian, menyebutkan bahwa Koperasi adalah badan usaha yang beranggotakan orang-orang atau badan hukum Koperasi dengan melandaskan kegiatannya berdasarkan prinsip Koperasi sekaligus sebagai gerakan ekonomi rakyat yang berdasar atas azas kekeluargaan dan kegotongroyongan. Gotong-royong merupakan sifat kepribadian bangsa Indonesia kita yang asli, dan lazimnya terdapat dalam masyarakat yang gemeinshaftlich (erat rasa persaudaraannya). Menurut CIA (Cooperative International Alliance) dalam (Kartasapoetra, 2007: 19) Koperasi adalah perkumpulan otonom dari orang atau badan yang bersatu secara sukarela untuk memenuhi kebutuhan dan aspirasi ekonomi, sosial dan budaya bersama melalui perusahaan yang dimiliki dan dikendalikan secara bersama dan tanggung jawab bersama terhadap akibat yang ada dan secara demokrasi.

Perangkat organisasi Koperasi terdiri dari: (a) Rapat anggota; (b) Pengurus; (c) Pengawas. Fungsi Koperasi: (1) alat perjuangan ekonomi untuk mempertinggi kesejahteraan rakyat; (2) alat pendemokrasian nasional; (3) sebagai salah satu urat nadi perekonomian bangsa Indonesia; (4) alat pembinaan insan masyarakat untuk memperkokoh kedudukan ekonomi bangsa Indonesia serta bersatu dalam mengatur tatalaksana perekonomian rakyat. Asas Koperasi adalah Kekeluargaan dan Kegotongroyongan. Pengurus Koperasi dapat mengangkat pengelola yang diberi wewenang untuk mengelola usaha Koperasi. Anggota Koperasi adalah pemilik dan sekaligus pengguna jasa Koperasi. Syarat keanggotaan diatur dalam AD dan ART.

\section{Koperasi Sekolah}

Koperasi sekolah adalah Koperasi yang didirikan di lingkungan sekolah yang anggotaanggotanya terdiri atas siswa sekolah. Koperasi sekolah didirikan dalam rangka menanamkan pendidikan Koperasi kepada siswa agar tujuan pengembangan Koperasi di Indonesia dapat terwujud. Landasan didirikannya Koperasi sekolah adalah keputusan bersama antara Departemen Transmigrasi dan Koperasi dengan Pendidikan dan Kebudayaan tanggal 16 Juli 1972 Nomor 275/SKPTS/ Mentranskop dan Nomor 0102/U/1983. Surat Keputusan Menteri Tenaga Kerja, Transmigrasi dan Koperasi Nomor 633/SKPTS/Men/ 1974, menjelaskan bahwa Koperasi sekolah adalah Koperasi yang didirikan di sekolah-sekolah SD, SMP, SMA, Madrasah dan pesantren.

Ciri-ciri Koperasi sekolah adalah: (1) Koperasi sekolah didirikan dalam rangka kegiatan belajar mengajar para siswa; (2) 
Anggotanya adalah kalangan siswa sekolah yang bersangkutan; (3) Tidak disyaratkan berbadan hukum; (4) Berfungsi sebagai laboratorium pengajaran Koperasi di sekolah. Tujuan didirikan Koperasi sekolah adalah untuk memajukan kesejahteraan anggota (warga sekolah) pada khususnya dan masyarakat pada umumnya, serta ikut membangun tata perekonomian nasional dalam rangka mewujudkan masyarakat yang adil dan makmur. Menurut SK bersama Departemen Transmigrasi dan Koperasi dengan Departemen Pendidikan dan Kebudayaan, tujuan pembentukan Koperasi sekolah adalah: (1) Mendidik, menanamkan, dan memelihara suatu kesadaran hidup bergotong royong dan setia kawan serta jiwa demokratis diantara para siswa; (2) Memupuk dan mendorong tumbuhnya kesadaran dan semangat Koperasi para siswa; (3) Meningkatkan pengetahuan dan keterampilan Koperasi dikalangan anggota yang berguna bagi para siswa untuk bekal terjun dimasyarakat; (4) Menunjang program pembangunan pemerintah di sektor perkoperasian melalui program pendidikan sekolah; (5) Membantu dan melayani pemenuhan kebutuhan ekonomi para siswa melalui pengembangan pembagian kegiatan usaha.

Koperasi sekolah dapat memberikan manfaat bagi siswa yaitu: (1) dapat digunakan sebagai sarana belajar berorganisasi, menjalankan usaha untuk kesejahteraan anggota; (2) memenuhi segala kebutuhan alat-alat pelajaran; (3) membentuk sikap mental yang baik, berdisiplin dan jujur di kalangan siswa; (4) melatih siswa untuk menabung; (5) memperoleh bagian Sisa Hasil Usaha (SHU); (6) melatih jiwa wirausaha di kalangan siswa; (7) menumbuhkan kompetensi siswa terhadap pemahaman sikap dan keterampilan berkoperasi untuk bekal hidup di masyarakat; (8) bagi pengurus memberi pengalaman untuk memimpin dan mengendalikan organisasi dan bisnis.

\section{Media Pembelajaran}

Media berasal dari kata medium yang secara harafiah berarti perantara atau pengantar pesan dari pengirim pesan ke penerima pesan (Arief S. Sadiman dkk, 2007: 6). Dalam bahasa arab media adalah perantara atau pengantar pesan dari pengirim pesan kepada penerima pesan (Azhar Arsyad, 2007: 3). Sedangkan media menurut Atwi Suparman
(2001: 187), adalah alat yang digunakan untuk menyalurkan pesan atau informasi dari pengirim kepada penerima pesan. Pengirim dan penerima pesan itu dapat berbentuk orang atau lembaga, sedangkan media tersebut dapat berupa alat-alat elektronik, gambar, buku dan sebagainya, sehingga bisa dipelajari secara mandiri sesuai dengan kemampuannya.

Smaldino, Lowther, \& Russell (2008: 372), menyatakan bahwa "a medium (plural, media) is a channel of communication. Derived from the latin word meaning "between," the term refers to anything that carrier information between a source and a receiver. Media merupakan sebuah komunikasi yang melibatkan antarsumber dan penerima. Dari beberapa pengertian yang telah dikemukakan di atas dapat dinyatakan bahwa media merupakan bentuk peralatan yang berfungsi merangsang pemikiran, pengantar pesan kepada sasaran dan dapat membangkitkan perasaan.

Dalam suatu proses pembelajaran, ada dua unsur yang sangat penting, yaitu metode pembelajaran dan media pembelajaran, yang harus dikuasai dan dipelajari oleh seorang pengajar. Media berfungsi untuk tujuan instruksi di mana informasi yang terdapat dalam media harus melibatkan siswa dalam benak atau mental maupun dalam bentuk yang nyata sehingga pembelajaran dapat terjadi. Yusufhadi Miarso (2005: 458), kegunaan media adalah: (a) mampu memberikan rangsangan yang bervariasi kepada otak, sehingga otak dapat berfungsi secara optimal; (b) dapat mengatasi keterbatasan pengalaman yang siswa; (c) dapat melampaui batas ruang kelas; (d) memungkinkan adanya interaksi langsung antara siswa dan lingkungan; (e) menghasilkan keseragaman pengamatan; (f) membangkitkan keinginan dan minat baru; (g) membangkitkan motivasi dan merangsang untuk belajar; (h) memberikan pengalaman yang integral/menyeluruh dari sesuatu yang konkrit maupun abstrak; (i) memberikan kesempatan kepada siswa untuk belajar mandiri, pada tempat dan waktu serta kecepatan yang ditentukan sendiri; (j) meningkatkan kemampuan keterbacaan baru; (k) mampu meningkatkan efek sosialisasi; (l) dapat meningkatkan kemampuan ekpresi diri pengajar maupun siswa. 


\section{Model Pembelajaran Sekolah Menengah Kejuruan (SMK)}

Thorndike (1965), belajar adalah proses interaksi antara stimulus (yang mungkin berupa pikiran, perasaan atau gerakan). Jelasnya perubahan tingkah laku itu bisa berupa sesuatu dapat diamati atau yang tidak bisa diamati. Menurut Klein (2002: 2),"Learning can be defines as an experimental process resulting in a relatively permanent change in behavior that cannot be explained by temporary states, maturation, or innate response tendencies". Artinya belajar dapat didefinisikan sebagai hasil proses eksperimental dalam perubahan tingkah laku yang relative permanen yang tidak dapat diucapkan dengan pernyataan sesaat. Waston (Suciati, 1996: 4), mengatakan bahwa belajar adalah proses interaksi antara stimulus dan respon, namun stimulus dan respon yang dimaksud harus berbentuk tingkah laku yang dapat diamati dan dapat diukur. Menurut Skinner (Dimyati, 2002: 9), belajar adalah suatu perilaku. Pada saat orang belajar, maka responnya menjadi lebih baik. Skinner menyatakan bahwa belajar ialah perubahan tingkah laku.

Menurut Syaiful Sagala (2010), model diartikan sebagai kerangka konseptual yang digunakan sebagai pedoman dalam melakukan kegiatan, adapun pembelajaran adalah membelajarkan siswa dengan menggunakan asas pendidikan maupun teori belajar. Menurut Joyce, \& Weil. (1985: 31), model memiliki banyak fungsi mulai perencanaan pelajaran, kurikulum sampai desain materi instruksionalnya. Sedangkan model pembelajaran itu sendiri adalah suatu desain atau pola dalam melakukan proses belajar mengajar. Ada empat model pembelajaran pendidikan kejuruan yang diterapkan di negara maju (Wardiman, 1998: 45), yaitu: Model Sekolah, Model Sistem Ganda, Model Magang dan model school-Based-entreprice, atau disebut dengan unit produksi. Menurut Joice, \& Weil. (1985: 34), ada beberapa model pembelajaran, antara lain: (1) information processing model; (2) Social Model; (3) personal model; dan (4) behavioral model. Greinert (1994), pakar pendidikan kejuruan dari Jerman, menyebutkan terdapat beberapa model dalam pendidikan kejuruan, yaitu: (1) model pasar (the market model); (2) model sekolah (the school model; dan (3) model sistem ganda (the dual system model).

\section{Pertanyaan Penelitian}

1. Bagaimana langkah pengembangan Model Kwu-Kop pembelajaran kewirausahaan di SMK ?

2. Perangkat apa saja yang dihasilkan dalam pengembangan Model Kwu-Kop pada pembelajaran kewirausahaan di SMK ?

3. Bagaimana validitas dan efektivitas Model Kwu-Kop pembelajaran kewirausahaan di SMK?

4. Bagaimana tingkat keterlaksanaan Model Kwu-Kop pembelajaran kewirausahaan di SMK ?

\section{METODE PENELITIAN}

\section{Prosedur Penelitian}

Penelitian ini menggunakan metode Penelitian dan Pengembangan atau Research and Development. Menurut Borg \& Gall (2003: 570), model ini memiliki sepuluh tahap pelaksanaan, namun dalam penelitian ini kami sederhanakan menjadi empat tahap yang terbagi dalam dua kegiatan yaitu: (1) prapengembangan terdiri: (a) tahap investigasi; (b) tahap desain; (c) tahap realisasi, dan pengembangan terdiri: (d) tahap evaluasi (validasi praktisi, ujicoba, revisi). Subjek uji coba adalah: (1) Guru kewirausahaan dan Siswa. Jenis data yang diperoleh adalah data kualitatif dan data kuantitatif.

\section{Teknik Analisis Data}

Sebelum instrumen digunakan di lapangan untuk mengukur kevalidan, keterlaksanaan dan keefektifan model, terlebih dahulu diuji validitas dan reliabiltasnya. Namun validitas instrumen yang berbentuk format validasi, lembar observasi, dan angket hanya diuji validitas teorinya melalui penilaian para ahli dan praktisi. Analisis yang diperlukan adalah:

\section{Analisis Keterlaksanaan Model}

Model dikatakan praktis dan mudah dilaksanakan apabila: (1) menurut penilaian dari praktisi menyatakan bahwa model dapat dengan mudah dilaksanakan dengan sedikit revisi; (2) secara nyata di lapangan model dapat diterapkan dan dapat terlaksana se- 
bagian walaupun tidak semua berdasarkan pengamatan; (3) Kemampuan guru mengelola pembelajaran dengan menggunakan model termasuk kategori minimal cukup baik.

\section{Analisis Keefektifan Model}

Model pembelajaran dikatakan efektif jika menurut penilaian praktisi berdasarkan pengetahuan dan pengalamannya menyatakan bahwa model yang dikembangkan efektif dan secara nyata di kelas pelaksanaannya efektif. Indikator adalah: (1) tujuan dari penerapan model pembelajaran tercapai, yaitu meningkatnya kualitas pembelajaran, dilihat dari pencapaian kompetensi belajar siswa secara klasikal $80 \%$ siswa mencapai nilai 70 ; (2) respon siswa terhadap model yang diungkapkan dalam perasaan, pendapat dan komentar positif; (3) aktivitas siswa dalam pembelajaran meningkat.

\section{Analisis Validitas Model}

Berdasarkan hasil validasi model dari praktisi, ditentukan nilai rata-rata dari nilai yang diberikan oleh penilai. Selanjutnya ditentukan nilai rata-rata validitas model, kemudian dirujuk pada pengkategorian interval kelas dari Riduwan (2009: 55), sbb:

$3,26 \leq \mathrm{M} \leq 4,00 \quad$ Kategori Dapat digunakan tanpa revisi

$2,51 \leq \mathrm{M} \leq 3,25$ Kategori Dapat digunakan dengan revisi kecil

$1,76 \leq \mathrm{M} \leq 2,50$ Kategori Dapat digunakan dengan revisi besar

$1,00 \leq \mathrm{M} \leq 1,75 \quad$ Kategori Tidak dapat digunakan

$\mathrm{M}=$ Rerata skor untuk aspek yang dinilai

Kriteria yang digunakan untuk menentukan bahwa instrumen memiliki derajat validitas yang memadai adalah apabila rerata (M) hasil dari keseluruhan aspek minimal dalam kategori valid, apabila tidak maka perlu diadakan revisi berdasarkan saran dari para validator sampai memenuhi nilai rerata minimal pada kategori valid. Untuk mengukur tingkat kesepakatan antarpenilai terhadap hasil validasi instrumen oleh para ahli (expert), dianalisis dengan statistik Coeffisient Cohen's Kappa dan Percentage of Agreements dari Nitko dan Brokhatr (2007: 80). Lembar penilaian dikatakan reliabel jika koefisien reliabilitasnya $(\mathrm{R}) \geq 0,70$.

\section{HASIL PENELITIAN}

\section{Penilaian Instrumen Penelitian}

Tabel 1. Hasil Penilaian Kelayakan Instrumen Penelitian

\begin{tabular}{|c|c|c|c|c|c|c|c|c|}
\hline \multirow[t]{2}{*}{ No } & \multirow[t]{2}{*}{ Nama Instrumen } & \multicolumn{4}{|c|}{ Hasil Penilaian } & \multirow{2}{*}{$\begin{array}{l}\text { Frek } \\
\text { LD }\end{array}$} & \multirow{2}{*}{$\begin{array}{c}\text { Frek } \\
\text { TD }\end{array}$} & \multirow[t]{2}{*}{ Ket. } \\
\hline & & 1 & 2 & 3 & 4 & & & \\
\hline 1 & Format Penilaian Model Kwu-Kop (FP-Model) & $\mathrm{LD}$ & LD & $\mathrm{LD}$ & LD & 4 & 0 & LD \\
\hline 2 & Format Penilaian RPP (FP-RPP) & $\mathrm{LD}$ & LD & LD & LD & 4 & 0 & $\mathrm{LD}$ \\
\hline 3 & $\begin{array}{l}\text { Format Penilaian Modul Pembelajaran (FP- } \\
\text { Modul) }\end{array}$ & $\mathrm{LD}$ & $\mathrm{LD}$ & $\mathrm{LD}$ & LD & 4 & 0 & LD \\
\hline 4 & $\begin{array}{l}\text { Format Penilaian Job Sheet } \\
\text { (FP-Job Sheet) }\end{array}$ & $\mathrm{LD}$ & $\mathrm{LD}$ & LD & LD & 4 & 0 & LD \\
\hline 5 & Format Penilaian Rubrik Penskoran (FP-Eval) & LD & $\mathrm{LD}$ & $\mathrm{LD}$ & LD & 4 & 0 & LD \\
\hline 6 & $\begin{array}{l}\text { Angket Keefektifan Model Respon Siswa (AK- } \\
\text { Siswa) }\end{array}$ & $\mathrm{LD}$ & $\mathrm{LD}$ & LD & LD & 4 & 0 & LD \\
\hline 7 & $\begin{array}{l}\text { Angket Keefektifan Model Respon Guru (AK- } \\
\text { Guru) }\end{array}$ & $\mathrm{LD}$ & $\mathrm{LD}$ & LD & LD & 4 & 0 & LD \\
\hline 8 & $\begin{array}{l}\text { Format Penilaian Keterlak sanaan Model (FP- } \\
\text { Laks) }\end{array}$ & LD & LD & LD & LD & 4 & 0 & LD \\
\hline 9 & Lembar Pengamatan Aktivitas Guru (LP-AG) & LD & LD & LD & LD & 4 & 0 & LD \\
\hline 10 & Lembar Pengamatan Perilaku Siswa (LP-PS) & LD & LD & LD & LD & 4 & 0 & LD \\
\hline
\end{tabular}


Hasil validasi oleh rater dari analisis statistik Coeffisient Cohen 'Kappa adalah:

Tabel 2. Hasil Validasi Instrumen oleh Rater

\begin{tabular}{clccc}
\hline No & \multicolumn{1}{c}{ Nama Instrumen } & $\begin{array}{c}\text { Koefisien } \\
\text { Reliabilitas }\end{array}$ & Kriteria & Keterangan \\
\hline 1 & $\begin{array}{l}\text { Format Penilaian Buku Panduan Model } \\
\text { Kwu-Kop }\end{array}$ & 0,87 & $\geq 0,70$ & Valid/Reliabel \\
2 & Format Penilaian RPP & 0,86 & $\geq 0,70$ & Valid/Reliabel \\
3 & Format Penilaian Modul Pembelajaran & 0,74 & $\geq 0,70$ & Valid/Reliabel \\
4 & Format Penilaian Job Sheet & 0,89 & $\geq 0,70$ & Valid/Reliabel \\
5 & Format Penilaian Rubrik Penskoran & 0,81 & $\geq 0,70$ & Valid/Reliabel \\
& Unjuk Kerja Siswa & 0,78 & $\geq 0,70$ & Valid/Reliabel \\
6 & Lembar Pengamatan Perilaku Siswa & 0,81 & $\geq 0,70$ & Valid/Reliabel \\
7 & $\begin{array}{l}\text { Lembar Pengamatan Aktivitas Guru } \\
\text { Dalam Pembelajaran }\end{array}$ & 0,74 & $\geq 0,70$ & Valid/Reliabel \\
8 & $\begin{array}{l}\text { Angket Efektifitas Model Kwu-Kop } \\
\text { (Respon Siswa) }\end{array}$ & 0,74 & $\geq 0,70$ & Valid/Reliabel \\
9 & $\begin{array}{l}\text { Angket Efektifitas Model Kwu-Kop } \\
\text { (Respon Guru) }\end{array}$ & 0,85 & $\geq 0,70$ & Valid/Reliabel \\
10 & $\begin{array}{l}\text { Lembar Pengamatan Keterlaksanaan } \\
\text { Model Kwu-Kop }\end{array}$ & & & \\
\hline
\end{tabular}

\section{Penilaian Model Kwu-Kop}

Tabel 3. Hasil Penilaian Buku Panduan Model Kwu-Kop

\begin{tabular}{lcc}
\hline \multicolumn{1}{c}{ Aspek yang dinilai } & \multicolumn{2}{c}{ Hasil Penilaian } \\
& Pra-UT & Stlh-UT \\
\hline Teori Pendukung & Baik & Baik Sekali \\
Prinsip Pengembangan Model Kwu-Kop & Baik & Baik \\
Pedoman Penggunaan Model Kwu-Kop & Baik & Baik \\
Mekanisme Pelaksanaan Model Kwu-Kop & Baik & Baik Sekali \\
Pedoman Penilaian Hasil belajar Siswa & Baik & Baik \\
\hline Penilaian Umum Buku Panduan Model Kwu-Kop & Baik & Baik Sekali \\
\hline
\end{tabular}

Tabel 4. Hasil Penilaian Perangkat Pembelajaran

\begin{tabular}{lccc}
\hline \multicolumn{1}{c}{ Perangkat Pembelajaran } & \multicolumn{3}{c}{ Hasil Penilaian } \\
& Pra-UT & Stlh-UT & Umum \\
\hline Rencana Pelaksanaan Pembelajaran & Baik & B S & Dapat digunakan \\
Modul Pembelajaran & Baik & B S & Dapat digunakan \\
Job Sheet & B S & B S & Dapat digunakan \\
Rubrik Penskoran Unjuk Kerja Siswa & Baik & B S & Dapat digunakan \\
\hline
\end{tabular}




\section{Hasil Pengembangan Model}

Tabel 5. Hasil Penilaian Efektifitas Model Kwu-Kop pada UT

\begin{tabular}{lcccc}
\hline \multirow{2}{*}{ Aspek yang dinilai } & \multicolumn{2}{c}{ Rata-rata Hasil Penilaian } & \multirow{2}{*}{ Rata-rata } & Keterangan \\
\cline { 2 - 3 } & Guru & Siswa & & \\
\hline Validitas & 3,50 & 3,75 & 3,63 & Dapat digunakan \\
Reliabilitas & 3,50 & 3,50 & 3,50 & Dapat digunakan \\
Objektifitas & 3,67 & 3,80 & 3,74 & Dapat digunakan \\
Praktis & 3,33 & 3,00 & 3,17 & Dapat digunakan \\
\hline \multicolumn{1}{c}{ Jumlah } & 3,50 & 3,51 & 3,50 & Dapat digunakan \\
\hline
\end{tabular}

Tabel 6. Hasil Penilaian Efektifitas Model Kwu-Kop pada UP

\begin{tabular}{lcccc}
\hline \multicolumn{1}{c}{ Aspek yang dinilai } & \multicolumn{2}{c}{ Rata-rata Hasil Penilaian } & Rata-rata & Keterangan \\
& Guru & Siswa & & \\
\hline Validitas & 3,75 & 4,00 & 3,88 & Dapat digunakan \\
Reliabilitas & 3,50 & 3,50 & 3,50 & Dapat digunakan \\
Objektifitas & 3,80 & 3,80 & 3,80 & Dapat digunakan \\
Praktis & 3,67 & 4,00 & 3,84 & Dapat digunakan \\
\hline \multicolumn{1}{c}{ Jumlah } & 3,68 & 3,83 & 3,75 & Dapat digunakan \\
\hline
\end{tabular}

Tabel 7. Pengamatan Keterlaksanaan Model Kwu-Kop pada UT dan UP

\begin{tabular}{ccccc}
\hline Pertemuan & \multicolumn{2}{c}{ Rata-rata (\%) Keterlaksanaan Model } & Rata-rata & Keterangan \\
& Ujicoba Terbatas & Ujicoba Diperluas & & \\
\hline 1 & 84,38 & 87,50 & 85,94 & Sangat Baik \\
2 & 93,75 & 93,75 & 93,75 & Sangat Baik \\
3 & 100,00 & 97,94 & 98,97 & Sangat Baik \\
\hline Rata-rata & 92,71 & 93,06 & 92,89 & Sangat Baik \\
\hline
\end{tabular}

Tabel 8. Pengamatan Aktivitas Guru Model Kwu-Kop pada UT dan UP

\begin{tabular}{ccccc}
\hline \multirow{2}{*}{ Pertemuan } & \multicolumn{2}{c}{ Rata-rata Aktivitas Guru } & Rata-rata & Keterangan \\
& Ujicoba Terbatas & Ujicoba Diperluas & & \\
\hline 1 & 2,83 & 2,99 & 2,91 & Baik \\
2 & 3,06 & 3,17 & 3,12 & Baik \\
3 & 3,18 & 3,30 & 3,24 & Baik \\
\hline Rata-rata & 3,02 & 3,15 & 3,09 & Baik \\
\hline
\end{tabular}

Tabel 9. Pengamatan Perilaku Siswa Model Kwu-Kop pada UT dan UP

\begin{tabular}{ccccc}
\hline Pertemuan & \multicolumn{2}{c}{ Rata-rata Perilaku Siswa } & Rata-rata & Keterangan \\
& Ujicoba Terbatas & Ujicoba Diperluas & & \\
\hline 1 & 3,04 & 3,04 & 3,04 & Baik \\
2 & 3,04 & 3,08 & 3,06 & Baik \\
3 & 3,05 & 3,10 & 3,08 & Baik \\
\hline Rata-rata & 3,04 & 3,07 & 3,06 & Baik \\
\hline
\end{tabular}




\section{Analisis Hasil Pra-ujicoba Terbatas (Pra-UT)}

Tabel 10. Data Penilaian Buku Panduan Model Kwu-Kop Pra-UT

\begin{tabular}{lcccccc}
\hline \multirow{2}{*}{ Komponen yang dinilai } & \multicolumn{4}{c}{ Frikuensi Nilai } & \multirow{2}{*}{ Kriteria } \\
\cline { 2 - 5 } & 1 & 2 & 3 & 4 & \\
\cline { 2 - 5 } Teori Pendukung (2 butir) & 0 & 0 & 6 & 2 & Baik \\
Prinsip Pengembangan Model (6 butir) & 0 & 0 & 13 & 11 & Baik \\
Pedoman Penggunaan Model (2 butir) & 0 & 0 & 4 & 4 & Baik \\
Prosedur Pelaksanaan Model (5 butir) & 0 & 0 & 13 & 7 & Baik \\
Pedoman Penilaian Hasil Belajar Siswa (3) & 0 & 0 & 8 & 4 & Baik \\
\hline Rerata Total Nilai & \multicolumn{4}{c}{3,38} & Baik \\
Penilaian Umum Model Kwu-Kop & \multicolumn{4}{c}{ Dapat digunakan dengan revisi kecil } \\
\hline
\end{tabular}

Tabel 11. Data Penilaian RPP Model Kwu-Kop Pra-UT

\begin{tabular}{lcccccl}
\hline \multirow{1}{*}{ Komponen yang dinilai } & \multicolumn{4}{c}{ Frikuensi Nilai } & \multirow{2}{*}{ Kriteria } \\
\cline { 2 - 6 } & 1 & 2 & 3 & 4 & \\
\hline Aspek Cakupan (2 butir) & 0 & 0 & 3 & 5 & B Sekali \\
Indikator Pencapaian (7 butir) & 0 & 0 & 18 & 10 & Baik \\
Isi dan Kegiatan Pembelajaran (5 butir) & 0 & 0 & 16 & 4 & Baik \\
Penggunaan Bahasa (4 butir) & 0 & 0 & 7 & 9 & B Sekali \\
Alokasi waktu (2 butir) & 0 & 0 & 7 & 1 & Baik \\
\hline Rerata Total Nilai & 3,37 & & Baik \\
Penilaian Umum terhadap RPP & Dapat digunakan dengan revisi kecil \\
\hline
\end{tabular}

Tabel 12. Data Penilaian Modul Pembelajaran Model Kwu-Kop Pra-UT

\begin{tabular}{lcccccc}
\hline \multirow{2}{*}{ Komponen yang dinilai } & \multicolumn{4}{c}{ Frikuensi Nilai } & \multirow{2}{*}{ Kriteria } \\
\cline { 2 - 5 } & 1 & 2 & 3 & 4 & \\
\hline Aspek Judul (7 butir) & 0 & 0 & 13 & 15 & B Sekali \\
Aspek Isi dan Materi Modul (8 butir) & 0 & 0 & 23 & 9 & Baik \\
Penggunaan Bahasa (4 butir) & 0 & 0 & 7 & 9 & B Sekali \\
\hline Rerata Total Nilai & \multicolumn{4}{c}{3,46} & Baik \\
Penilaian Umum terhadap Modul & \multicolumn{4}{c}{ Dapat digunakan dengan revisi kecil } \\
\hline
\end{tabular}

Tabel 13. Data Penilaian Job Sheet Model Kwu-Kop Pra-UT

\begin{tabular}{lcccccc}
\hline \multirow{2}{*}{ Komponen yang dinilai } & \multicolumn{4}{c}{ Frikuensi Nilai } & \multirow{2}{*}{ Kriteria } \\
\cline { 2 - 6 } & 1 & 2 & 3 & 4 & \\
\hline Aspek Cakupan (3 butir) & 0 & 0 & 6 & 6 & Baik \\
Aspek Isi (6 butir) & 0 & 0 & 15 & 9 & Baik \\
Penggunaan Bahasa (4 butir) & 0 & 0 & 4 & 12 & B Sekali \\
\hline Rerata Total Nilai & \multicolumn{4}{c}{3,54} & B Sekali \\
Penilaian Umum terhadap Job Sheet & Dapat digunakan dengan revisi kecil \\
\hline
\end{tabular}


Tabel 14. Data Penilaian Rubrik Penskoran Model Kwu-Kop Pra-UT

\begin{tabular}{lcccccc}
\hline \multirow{2}{*}{ Komponen yang dinilai } & \multicolumn{4}{c}{ Frikuensi Nilai } & \multirow{2}{*}{ Kriteria } \\
\cline { 2 - 5 } & 1 & 2 & 3 & 4 & \\
\hline Aspek Petunjuk (2 butir) & 0 & 0 & 6 & 2 & Baik \\
Aspek Cakupan (4 butir) & 0 & 0 & 11 & 5 & Baik \\
Penggunaan Bahasa (2 butir) & 0 & 0 & 2 & 6 & B Sekali \\
\hline Rerata Total Nilai & \multicolumn{4}{c}{3,44} & Baik \\
Penilaian Umum Rubrik Penskoran & Dapat digunakan dengan revisi kecil \\
\hline
\end{tabular}

\section{Analisis Hasil Setelah Ujicoba Terbatas (Stlh-UT)}

Tabel 15. Data Penilaian Buku Panduan Model Kwu-Kop Setelah-UT

\begin{tabular}{lllllll}
\hline \multirow{2}{*}{ Komponen yang dinilai } & \multicolumn{4}{c}{ Frikuensi Nilai } & \multirow{2}{*}{ Kriteria } \\
\cline { 2 - 5 } & 1 & 2 & 3 & 4 & \\
\hline Teori Pendukung (2 butir) & 0 & 0 & 1 & 3 & B Sekali \\
Prinsip Pengembangan Model (6 butir) & 0 & 0 & 6 & 6 & Baik \\
Pedoman Penggunaan Model (2 butir) & 0 & 0 & 3 & 1 & Baik \\
Prosedur Pelaksanaan Model (5 butir) & 0 & 0 & 3 & 7 & B Sekali \\
Pedoman Penilaian Hasil Belajar Siswa (3) & 0 & 0 & 3 & 3 & Baik \\
\hline Rerata Total Nilai & \multicolumn{4}{c}{3,54} & B Sekali \\
Penilaian Umum Model Kwu-Kop & \multicolumn{4}{c}{ Dapat digunakan dengan revisi kecil } \\
\hline
\end{tabular}

Tabel 16. Data Penilaian RPP Model Kwu-Kop Setelah-UT

\begin{tabular}{lllllll}
\hline \multirow{2}{*}{ Komponen yang dinilai } & \multicolumn{4}{c}{ Frikuensi Nilai } & \multirow{2}{*}{ Kriteria } \\
\cline { 2 - 5 } & 1 & 2 & 3 & 4 \\
\hline Aspek Cakupan (2 butir) & 0 & 0 & 1 & 3 & B Sekali \\
Indikator Pencapaian (7 butir) & 0 & 0 & 7 & 7 & Baik \\
Isi dan Kegiatan Pembelajaran (5 butir) & 0 & 0 & 5 & 5 & Baik \\
Penggunaan Bahasa (4 butir) & 0 & 0 & 3 & 5 & B Sekali \\
Alokasi waktu (2 butir) & 0 & 0 & 1 & 3 & Baik \\
Rerata Total Nilai & \multicolumn{4}{c}{3,63} & B Sekali \\
Penilaian Umum terhadap RPP & Dapat digunakan dengan revisi kecil \\
\hline
\end{tabular}

Tabel 17. Data Penilaian Modul Pembelajaran Model Kwu-Kop Setelah-UT

\begin{tabular}{lllllll}
\hline \multirow{2}{*}{ Komponen yang dinilai } & \multicolumn{4}{c}{ Frikuensi Nilai } & Kriteria \\
\cline { 2 - 5 } & 1 & 2 & 3 & 4 & \\
\hline Aspek Judul (7 butir) & 0 & 0 & 7 & 7 & Baik \\
Aspek Isi dan Materi Modul (8 butir) & 0 & 0 & 9 & 7 & Baik \\
Penggunaan Bahasa (4 butir) & 0 & 0 & 3 & 5 & B Sekali \\
\hline Rerata Total Nilai & \multicolumn{4}{c}{3,53} & & B Sekali \\
Penilaian Umum terhadap Modul & \multicolumn{4}{c}{ Dapat digunakan dengan revisi kecil } \\
\hline
\end{tabular}


Tabel 18. Data Penilaian Job Sheet Model Kwu-Kop Setelah-UT

\begin{tabular}{lllllll}
\hline \multirow{1}{*}{ Komponen yang dinilai } & \multicolumn{4}{c}{ Frikuensi Nilai } & Kriteria \\
\cline { 2 - 5 } & 1 & 2 & 3 & 4 & \\
\hline Aspek Cakupan (3 butir) & 0 & 0 & 3 & 3 & Baik \\
Aspek Isi (6 butir) & 0 & 0 & 5 & 7 & B Sekali \\
Penggunaan Bahasa (4 butir) & 0 & 0 & 2 & 6 & B Sekali \\
\hline Rerata Total Nilai & \multicolumn{4}{c}{3,61} & B Sekali \\
Penilaian Umum terhadap Job Sheet & \multicolumn{4}{c}{ Dapat digunakan dengan revisi kecil } \\
\hline
\end{tabular}

Tabel 19. Data Penilaian Rubrik Penskoran Model Kwu-Kop Setelah-UT

\begin{tabular}{lllllll}
\hline \multirow{2}{*}{ Komponen yang dinilai } & \multicolumn{4}{c}{ Frikuensi Nilai } & \multirow{2}{*}{ Kriteria } \\
\cline { 2 - 6 } & 1 & 2 & 3 & 4 & \\
\hline Aspek Petunjuk (2 butir) & 0 & 0 & 2 & 2 & Baik \\
Aspek Cakupan (4 butir) & 0 & 0 & 3 & 5 & B Sekali \\
Penggunaan Bahasa (2 butir) & 0 & 0 & 1 & 3 & B Sekali \\
\hline Rerata Total Nilai & \multicolumn{4}{c}{3,63} & B Sekali \\
Penilaian Umum Rubrik Penskoran & \multicolumn{4}{c}{ Dapat digunakan dengan revisi kecil } \\
\hline
\end{tabular}

\section{Keterlaksanaan Model Kwu-Kop pada UT}

Tabel 20. Percentage of Agreement Pengamatan Keterlaksanaan Model Kwu-Kop (UT)

\begin{tabular}{cccc}
\hline Penilaian ke- & \multicolumn{3}{c}{ Hasil Pengamatan Keterlaksanaan Model } \\
\cline { 2 - 4 } & A & D & PA \\
\hline 1 & 15 & 1 & 94 \\
2 & 16 & 0 & 100 \\
3 & 16 & 0 & 100 \\
Rerata & 15,67 & 0,33 & 98 \\
\hline
\end{tabular}

Keterangan: A: Agreement, D: Disagreement, PA: Percentage of Agreement

Tabel 21. Hasil Pengamatan Keterlaksanaan Model Kwu-Kop Pada UT

\begin{tabular}{cccc}
\hline Penilaian ke- & \multicolumn{2}{c}{ Persentase Keterlaksanaan } & \multirow{2}{*}{ Keterangan } \\
\cline { 2 - 3 } & Rerata Skor & $\%$ & \\
\hline 1 & 13,5 & 84,38 & Sangat Baik \\
2 & 15 & 93,75 & Sangat Baik \\
3 & 16 & 100,00 & Sangat Baik \\
\hline Rerata & 14,89 & 93,06 & Sangat Baik \\
\hline
\end{tabular}




\section{Keterlaksanaan Model Kwu-Kop pada UP}

Tabel 22. Percentage of Agreement Pengamatan Keterlaksanaan Model Kwu-Kop pada UP

\begin{tabular}{cccc}
\hline Penilaian ke- & \multicolumn{3}{c}{ Hasil Pengmatan Keterlaksanaan Model } \\
& A & D & PA \\
\hline 1 & 14,67 & 1,33 & 92 \\
2 & 15,33 & 0,67 & 96 \\
3 & 16 & 0 & 100 \\
\hline Rerata & 15,33 & 0,67 & 96 \\
\hline
\end{tabular}

Keterangan: A: Agreement, D: Disagreement, PA: Percentage of Agreement

Tabel 23. Pengamatan Keterlaksanaan Model Kwu-Kop pada UP

\begin{tabular}{cccl}
\hline Penilaian ke- & \multicolumn{2}{c}{ Persentase Keterlaksanaan } & Keterangan \\
& Rerata Skor & $\%$ & \\
\hline 1 & 14 & 87,50 & Sangat Baik \\
2 & 15 & 93,75 & Sangat Baik \\
3 & 15,67 & 97,94 & Sangat Baik \\
\hline Rerata & 14,89 & 93,06 & Sangat Baik \\
\hline
\end{tabular}

\section{SIMPULAN DAN SARAN}

\section{Simpulan}

1. Langkah pengembangan model pembelajaran Model Kwu-Kop dibagi dalam dua kegiatan dan terbagi dalam empat tahap, yaitu: (a) prapengembangan, meliputi tahap investigasi, tahap desain, dan tahap realisasi; (b) pengembangan, ini merupakan tahap evaluasi, kegiatannya meliputi validasi, uji coba dan revisi.

2. Perangkat pembelajaran Model Kwu-Kop yang dikembangkan dapat dikatakan sederhana sehingga dapat dengan mudah dipahami, baik oleh guru maupun siswa. Perangkat yang dikembangkan berupa buku panduan Model Kwu-Kop dan perangkat pembelajaran. Buku panduan Model Kwu-Kop berisi: (a) Rasionalitas dan teori pendukung Model Kwu-Kop; (b) Prinsip pembelajaran Model KwuKop; (c) Prosedur Pelaksanaan Model Kwu-Kop; (d) Pedoman penilaian hasil belajar siswa; dan (e) Tahapan pengolahan hasil belajar siswa. Sedangkan perangkat pembelajaran terdiri dari: (a)
RPP; (b) modul pembelajaran; (c) job sheet; (d) perangkat evaluasi.

3. Berdasarkan hasil analisis kevalidan menunjukkan bahwa semua validator menyatakan bahwa Model Kwu-Kop beserta perangkatnya dapat digunakan dalam pembelajaran praktik kewirausahaan di SMK, karena dibangun atas landasan berfikir yang rasional dengan teori pendukung yang kuat dan relevan. Maka dapat disimpulkan bahwa pembelajaran Model Kwu-Kop yang dihasilkan memenuhi kriteria valid untuk dipergunakan di SMK Kelompok Bisnsis dan Manajemen.

4. Berdasarkan analisis angket keefektifan terhadap penerapan Model Kwu-Kop, menunjukkan bahwa respon siswa maupun respon guru positif dan secara obyektif baik siswa maupun guru mengatakan bahwa model ini efektif untuk menumbuhkan keterampilan kewirausahaan siswa SMK Kelompok Bisnis dan Manajemen.

5. Berdasarkan hasil analisis keterlaksanaan Model Kwu-Kop, dapat disimpulkan bahwa penerapan Model Kwu-Kop dalam pembelajaran kewirausahaan SMK 
dapat dilaksanakan dengan praktis dan dapat berfungsi dengan baik untuk menumbuhkan keterampilan kewirausahaan siswa SMK Kelompok Bisnis dan Manajemen.

\section{Saran}

Pengembangan Model Kwu-Kop dalam penelitian ini baru sebatas pada pengujian model, disarankan kepada guru pengajar kewirausahaan untuk implementasi dan sosialisasi penggunaan model ini di SMK, dan diadakan penelitian lain untuk pengembangan lebih lanjut.

Perangkat dari Model Kwu-Kop dari hasil penelitian ini masih relatif sederhana. Disarankan ada penelitian lebih lanjut untuk mengembangkan model, sehingga menjadi model yang lebih lengkap dan lebih efektif untuk meningkatkan keterampilan kewirausahaan siswa SMK.

Pembentukan kompetensi dalam Model Kwu-Kop implementasinya pada badan usaha yang berbentuk Koperasi, disarankan kepada guru kewirausahaan untuk bisa mengimplementasikan pada bentuk badan usaha yang lain. Sehingga pada saat diskusi dan presentasi dengan siswa, guru bisa menjelaskan apa yang membedakan dalam pengelolaan Koperasi dengan pengelolaan bentuk badan usaha yang lain.

Model Kwu-Kop ini sangat efektif dan praktis, hal ini tebukti mendapat respon yang positif baik dari siswa maupun guru, disarankan kepada para kepala sekolah SMK Kelompok Bisnis dan Manajemen agar mempertimbangkan Model Kwu-Kop ini sebagai model pembelajaran kewirausahaan yang siap diimplementasikan di SMK.

Pelaksanaan Model Kwu-Kop untuk siswa SMK kelas XII semester ganjil dan genap, yang mana pada saat ini siswa juga terbebani untuk menghadapi Ujian Akhir Nasional (UNAS), untuk itu disarankan kepada guru kewirausahaan supaya materi pembelajaran Model Kwu-Kop dituntaskan pada akhir semester ganjil. Sehingga siswa disemester genap cukup waktu untuk belajar menghadapi UNAS, tidak lagi terbebani oleh pembelajaran kewirausahaan.

\section{DAFTAR PUSTAKA}

Arif S. Sadiman., R. Raharjo., \& Anung Haryono. (2007). Media pendidikan : Pengertian, pengembangan dan pemanfaatannya. Jakarta: PT. Raja Grafindo Perkasa.

Arifin Chaniago. (1982). Perkoperasian Indonesia. Bandung: Angkasa.

Atwi Suparman. (2001). Desain instruksional. Jakarta: Proyek Pengembangan Universitas Terbuka. Direktorat Jenderal Pendidikan Tinggi. Jakarta: Departemen Pendidikan Nasional.

Azhar Arsyad. (2007). Media pembelajaran. Jakarta: PT. Raja Grafindo Persada.

Badan Pusat Statistik. (2009). Perkembangan beberapa indikator utama sosialekonomi Indonesia pada bulan Maret 2009. Jakarta: Badan Pusat Statistik.

Boediono. (3-Desember-2012). Wirausahawan Indonesia cuma 1,56 persen. Tabengan hal. 9 kol. 1.

Borg, W.R., \& Gall, M.D. (2003). Educational research, An introduction $\left(5^{\text {th }}\right.$ ed.). New York: Logman.

Bruce, J., \& Weil, M. (1985). Models of teaching. Englewood Cliffs, New Jersey: Prentice-Hall.

Buchori Alma. (2005). Kewirausahaan. Bandung: Alfabeta.

Depdiknas. (2003). Undang-undang RI Nomor 20, tahun 2003, tentang Sistem Pendidikan Nasional. Jakarta: Departemen Pendidikan Nasional.

Depdiknas. (2004). Pola pengembangan pembinaan penyelenggaraan program kewirausahaan Sekolah Menengah Kejuruan tahun 2004. Jakarta: Depdiknas.

Depdiknas. (2010). Rencana strategis Departemen Pendidikan Nasional tahun 2010-2914: Menuju pembangunan pendidikan nasional jangka panjang 2025. Jakarta: Departemen Pendidikan Nasional.

Dimyati., \& Mudjiono. (2002). Belajar dan pembelajaran. Jakarta: PT Rineka Cipta. 
Greinert, W.D. (2009). Basic type of vocational qualification. Tubingen: Institute of Scientific Cooperation (Ed).

Hendrojogi. (1999). Koperasi, asas-asas teori dan praktek. Jakarta: PT Raja Grafindo Persada.

Heru Kristanto. (2009). Kewirausahaan: Enterpreneurship pendekatan manajemen dan praktis. Jogyakarta: Graha Ilmu.

Hisrich, D.R., \& Peter, P.M. (1989). Entrepreneurship. Fifth Edition, North America: Mc Graw-Hill.

Irmawita. (2003). Analisa pengembangan wirausaha melalui pendidikan kewirausahaan pada industri kecil di Kabupaten Tanah Datar. Jurnal Ilmiah. VISI Nomor 14/THXI/2003, 45-47.

Kartasapoetra., Bambang., \& Setiady. (2007). Koperasi Indonesia buku acuan untuk siswa SMK. Jakarta: Kerjasama Rineka Cipta dan Bina Adiaksara.

Klein, S.B. (2002). Learning principle and applications. USA: Mississippi State University.

Kuratko., Donald., \& Hodgetts, R. (2004). Enterpreneurship: Theory, process and practice $\left(6^{\text {th }}\right.$ ed.). Canada: Thomson South-Western.

Lambing., Paggy, A., \& Kuehl. (2000). Entrepreneurship. New Jersey: Prentice Hall Inc.

Longenecker, J.G. (2001). Kewirausahaan manajemen usaha kecil. Jakarta: Salemba Empat.

Maskur Wiratmo. (1996). Pengantar kewirausahaan, kerangka dasar memasuki dunia bisnis. Yogyakarta: BPFE.

Nitko, A.J., \& Brookhart, S.M. (2007). Educational assessment of students. New Jersey: Pearson Merrill Prentice hall.
Reuter, E. B. (2006). The social attitude. The University Of Lowa. Diambil pada 21 Agustus 2006. http://spartan.ac.brocku.ca/"reuter/reuter-1923.html.

Riduwan. (2009). Pengantar statistik sosial. Bandung: Alfabeta.

Smaldino, S.I., Lowther, D.S., \& Russell, J.D. (2008). Instructional technology and media for learning (9 th, ed.). New Jersey: Peerson.

Suryana. (2003). Kewirausahaan: Pedoman praktis, kiat dan proses menuju sukses. Jakarta: Salemba Empat.

Surya Dharma. (2009). Kewirausahaan sekolah berbasis kreativitas dan inovasi. Jurnal Pendidikan dan Kebudayaan. Volume. 15. Edisi Khusus I, 2009, 102121.

Syaiful Sagala. (2010). Konsep dan makna pembelajaran: Untuk membantu memecahkan problematika belajar dan mengajar. Bandung: Alfabeta.

Thorndike., Edwar, L., \& Elizabeth, H. (1965). Measuremant and evaluation in psychology and education. New York: John Wiley.

Undang-undang. (1992). UU Nomor. 25 Tahun 1992. Tentang perkoperasian.

Wardiman Djojonegoro. (1998). Pengembangan sumber daya manusia melalui Sekolah Menengah Kejuruan (SMK). Jakarta: PT Jayakarta Agung Offset.

Zimmerer, T. W., Scarborough, N.M., \& Wilson, D. (2008). Essentials of entrepreneurship and small business management $\left(4^{\text {th }}\right.$ ed.). New Jersey: Pearson Education, Inc.

Zimmerer, T.W., \& Scarborough, N.M. (2005). Entrepreneurship and the new ventureformation. New Jersey: Prentice Hall International. 